[Article]

\title{
基团贡献法在估算反应热过程中的系统性验证及校正
}

\author{
王 点 ${ }^{1}$ 郝 琳 $^{1, *}$ 杨晓武 ${ }^{2}$ 郭子超 ${ }^{1}$ 白文帅 ${ }^{1}$ 李 帅 $^{1}$ 卫宏远 ${ }^{1}$

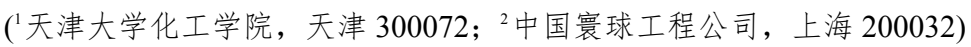

摘要: 在进行化工过程危险评估和安全设计时, 反应热是一项非常重要的热力学参数。通常情况有两种方法 获得反应热: 量热法与估算法。相比来说, 量热法的结果更精确, 但所需时间和费用较多, 也经常由于实验 条件的限制无法进行; 而估算法相比来说更便捷, 但结果却不够准确。基团贡献法(GCM)就是一种常见的估 算法。为了系统地研究估算法的准确度, 从而使其能够在工业生产中对反应热进行初管, 本文分别通过量热 实验法和 GCM 估算得到了包括 11 种常见反应类型在内的 33 个反应的反应热, 并对结果进行了详细对比; 按 照反应类型对量热结果 $\left(Q_{\text {calorimetry }}\right)$ 和估算结果 $\left(Q_{\mathrm{GCM}}\right)$ 之间的误差进行了总结; 根据相对误差范围, 反应类型被 分为不同的组从而能够将 $Q_{\mathrm{GCM}}$ 校正为 $Q_{\mathrm{calarimetr}}$; 并且针对不同的反应类型, 提出了一些校正系数将 $Q_{\mathrm{GCM}}$ 校正 为 $Q_{\text {recommended }}\left(Q_{\mathrm{r}}\right)$, 使得 GCM 在工业应用中, 量热方法不方便的时候可以服务生产。最后, 本文对误差来源 进行了详细的分析, 并且为如何能够估算得更准确提出了一些建议。

关键词: 反应热; 量热; 基团贡献法; 误差分析; 校正系数

中图分类号: 0642

\section{Systematic Verification and Correction of the Group Contribution Method for Estimating Chemical Reaction Heats}

\author{
WANG Rui $\quad$ HAO Lin ${ }^{1, *} \quad$ YANG Xiao-Wu² $\quad$ GUO Zi-Chao ${ }^{1}$ \\ BAI Wen-Shuai ${ }^{1}$ LI Shuai ${ }^{1} \quad$ WEI Hong-Yuan ${ }^{1}$ \\ ('School of Chemical Engineering and Technology, Tianjin University, Tianjin 300072, P. R. China; \\ ${ }^{2}$ China Huanqiu Contracting \& Engineering Corporation, Shanghai 200032, P. R. China)
}

\begin{abstract}
Reaction heat $(Q)$ is an important parameter in chemical thermodynamics that is widely used in the hazard evaluation and safety design of chemical processes. Reaction heats can be obtained by either calorimetry or estimation. Calorimetry is generally more accurate, but is time-consuming, and sometimes precluded by the experimental conditions. By comparison, estimation techniques are quick and convenient, but are necessarily less accurate. The group contribution method (GCM) is one of the most commonly used estimation techniques. To investigate the accuracy of the estimations and make a primary screening of reaction heats for the industrial application of the GCM, calorimetric measurements of 33 reactions of 11 reaction types, including hydrogenation, reduction, nitration, oxidation, amidation, amination, ester hydrolysis, nitrogen substitution, ring-opening, and esterification, were conducted. The 33 reaction heats were also estimated by the GCM, and were compared with the calorimetric results. The relative errors between calorimetry $\left(Q_{\text {calorimetry }}\right)$ and the GCM $\left(Q_{\mathrm{GCM}}\right)$ were also summarized for the different types of reactions. According to the range of relative errors, the reaction types were divided into different groups for calibrating $Q_{\mathrm{GCM}}$ to $Q_{\text {calorimetry. }}$ Some recommended correction coefficients were proposed to correct $Q_{\mathrm{GCM}}$ to $Q_{\text {recommended }}\left(Q_{r}\right)$ for the different types of reactions, which could be employed in industrial settings where
\end{abstract}

Received: February 15, 2016; Revised: March 16, 2016; Published on Web: March 16, 2016.

*Corresponding author. Email: haolin@tju.edu.cn; Tel: +86-22-27405754.

The project was supported by the National Natural Science Foundation of China (21576196)

国家自然科学基金(21576196)资助项目

(c) Editorial office of Acta Physico-Chimica Sinica 
experimental results are difficult to acquire. Finally, the sources of error between $Q_{\text {calorimetry }}$ and $Q_{\mathrm{Gcm}}$ were analyzed, and advice for making accurate estimations was proposed for future work.

\section{Key Words: Reaction heat; Calorimetry; Group contribution method; Error analysis; Correction coefficient}

\section{Introduction}

The heat of a reaction $(Q)$ is one of the most important thermodynamic parameters in chemical process hazard evaluation and safety design. It can be used to calculate the adiabatic temperature rise and the maximum temperature of the synthesis reaction (MTSR) to determine the thermodynamic worst case scenario. Obtaining the heat of a reaction is the first step of a chemical process design.

There are two ways to obtain the reaction heat: calorimetry and estimation techniques ${ }^{1}$.

Calorimetry is a well-accepted relatively accurate method as measuring the reaction heat for industrial processes. However, it is time consuming and sometimes is not easy to thoroughly simulate a number of extreme situations in a calorimetry reactor, such as extreme high pressures, low temperatures, hydrogen, chlorine, and any other corrosive dangerous gas reactant. Therefore, using calorimetry to measure reaction heats is not always practical, feasible or required ${ }^{2}$.

As a comparison, estimation techniques are cheaper and more convenient ${ }^{3}$. Reaction heats can be obtained without considering the trying conditions. Some of the common estimation techniques are the quantum mechanics method, molecular mechanics method, and the group contribution method (GCM $)^{4,5}$. The quantum mechanics approach is mainly based on the wave function and the molecular mechanics obtains the molecular information by using mechanics equations ${ }^{6,7}$. Since highly relying on theoretical basis, these two methods will lead to a large deviation from the actual situation sometimes.

GCM is a typical method of reaction heat prediction. A basic assumption of the GCM is that the physics properties of pure compounds or mixtures equal the sum of all the chemical functional groups' contributions. Since its extensive universality, the GCM is one of the most promising estimation techniques for industry.

Over one hundred chemical functional groups make up all the compounds. If the physics properties of these groups are known, the properties of compounds will be obtained by GCM. Many researches have been done about this topic. For the estimation of properties of pure compounds, the GCMs given by Joback and Reid $^{8}$, Lydersen $^{9}$, Ambrose $^{10}$, Klincewicz and Reid ${ }^{11}$, Lyman et al. ${ }^{12}$, and Horvath ${ }^{13}$ have been widely used. In these methods, the property of a compound is a function of structurally-dependent parameters, which are determined by summing the frequency of each group occurring in the molecule times its contribution.

At early times, divisions of groups were coarse and had less consideration about the interactions among groups. Later, more correction terms were proposed and the interactions were taken into account, and then it reflected in the calculation of saturated vapor pressure $^{14}$, enthalpy of formation ${ }^{15}$, enthalpy of evapora$\operatorname{tion}^{16,17}$, heat capacity ${ }^{18}$, melting point ${ }^{19}$ and so on.

Research of the GCM keeps attracting increasing attention in these years. The applications of the GCM have extended to the determination of thermal conductivity of liquid chemicals ${ }^{20}$, the prediction of enthalpy of fusion of pure compounds ${ }^{21}$, the radiative efficiency estimation of organic substance ${ }^{22}$, as well as the fields of heavy petroleum fluids ${ }^{23}$, vegetable oils, and biodiesel ${ }^{24}$. Moreover, a great part of the recent researches on the GCM focuses on the applications of ionic liquids ${ }^{25-31}$. Just a few studies are relevant with reaction enthalpy, such as predictions of standard enthalpy of formation by the $\mathrm{GCM}^{32}$. However, few studies have been carried out on the verification and application of the GCM in estimating reaction heat.

The GCM has been widely applied in the petrochemical and pharmaceutical industry and is of great value in the chemical thermodynamic and hazard evaluation area. Since chemical industry operation condition is always so harsh that calorimetry is hard to conduct, and just by calorimetry or consulting literature to get the reaction heats seems not reliable. On this condition, the GCM will be effective. It is convenient to estimate the heats of reactions by the GCM.

However, the GCM can't perfectly describe the real process since it works mainly relying on the formation and rupture of chemical bonds, but ignoring many factors like physical process heat effects, side reactions and conversion and so on. As a consequence, it will be risky to apply estimated data directly into a real production process. Since few studies have been carried out to focus on verifications and applications of the GCM, some work has been done in this paper to compare a series of the GCM based predicting values with experimental ones of reaction heat data, propose some corresponding intervals and recommended correction coefficients for different types of reactions which could be applied in process safety evaluations when experimental data are difficult to get. Some advice and error sources on industrial applications of the GCM have been proposed.

\section{Experimental}

Thirty three typical experiments were conducted by using an HEL SIMULAR reaction calorimeter, which is a tool that allows for the precise simulation and thermal study of a chemistry and associated plant. Subsequently, important safety, viability, and optimization data can be obtained prior to scale up. The reactor is a $1 \mathrm{~L}$ double jacketed glass vessel with slightly narrowing diameter walls ( $\Phi_{\text {average }} 90 \mathrm{~mm}$ ). Agitation is achieved through stirring $\left(0-600 \mathrm{r} \cdot \mathrm{min}^{-1}\right.$; glass pitched blade impeller $\left.\Phi 45 \mathrm{~mm}\right)$, precise 
temperature control is achieved using an external cooling system with oil flowing through the jacket together with a regulated electrical heater $(0-150 \mathrm{~W})$ inside the vessel. In addition the reactor is equipped with solid and liquid dosing units, a liquid sampling unit, an inlet gas mass flow controller, and a temperature probe (Pt 100). The sketch map of SIMULAR calorimeter is shown as Fig.1.

SIMULAR is designed to be a power compensation calorimetry. The basic principle of the power compensation is the heat balance equation (1). The theories of isothermal reaction calorimeter and power-compensation have been reported in detail $1^{33,34}$.

$$
q_{\text {flow }}+q_{\text {loss }}=q_{\mathrm{r}}+q_{\text {feed }}+q_{\text {compensation }}
$$

where $q_{\text {flow }}, q_{\text {loss }}, q_{\mathrm{r}}, q_{\text {feed }}, q_{\text {compensation }}$ are terms of thermal power owning to heat flow, loss, reaction, feed, compensation heater.

The 33 experiments were all conducted under the identical conditions and steps with the industrial conditions. Since the real production process design package need to be protected for the intellectual property, some groups not related to the reaction are replaced to " $\mathrm{R}$ ". Calorimetry data are listed in Table 1 . In order to get a clear grasp of different kinds of common types of reactions, the 33 experiments were also divided into 11 common chemical reaction types according to the reaction functional group, which can help summarize the average errors of different types of reactions and apply in the practical industry.

\section{Estimation section}

Among all GCM for estimating reaction heats, Benson GCM is the most widely used one $\mathrm{e}^{5,3539}$. Meanwhile, the software CHETAH (CHEmical Thermodynamic And Hazard evaluation) programmed by Benson (ASTM) is widely used all through the estimation technique areas $^{40}$.

The Benson GCM can only acquire the standard enthalpies of formation directly instead of heats of reaction. For a hypothetical reaction:

$a \mathrm{~A}+b \mathrm{~B}+\cdots \underline{\text { certain conditions }} c \mathrm{C}+d \mathrm{D}+\cdots$

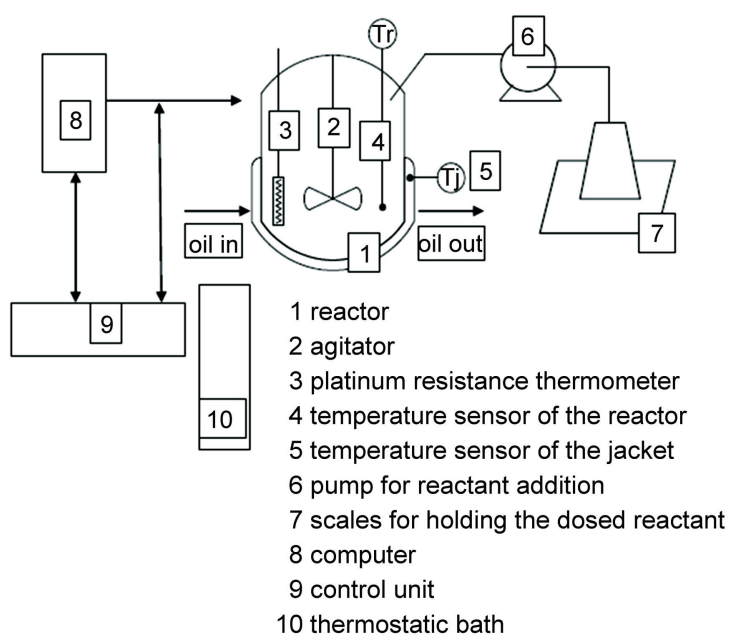

Fig.1 Sketch map of SIMULAR calorimeter $\mathrm{Tr}$ : the temperature of the reactor, $\mathrm{Tj}$ : the temperature of the jacket

$$
\Delta H_{\mathrm{r}}^{\ominus}=\sum_{i} v_{i} \Delta H_{\mathrm{f}}^{\ominus}(i)
$$

where $\Delta H_{\mathrm{r}}^{\ominus}$ is the enthalpy of reaction, which equals the reaction heat in number, $v$ is the reaction coefficient, $i$ is reactant or product, and $\Delta H_{\mathrm{f}}^{\ominus}$ is the standard enthalpy of formation. The enthalpy of reaction can be calculated by the sum of the enthalpies of formation (suppose that products have positive reaction coefficients and reactants have negative ones $)^{41-44}$. The standard enthalpies of formation by Benson methods are based on gas state, which can be converted to reaction temperatures from standard temperatures by using specific heat capacity, and adding vaporization heat can finally change gas states to real phase states. Eventually, the enthalpy of reaction by the GCM is acquired.

According to the Benson GCM basic assumption, the physics properties of pure compounds or mixtures equal the sum of all the groups' contributions. Every different group has its own "heat" and "heat capacity". Therefore, the same groups in the reactants and the products can be counteracted, only leaving the groups actually involved in the reaction. The complex equation hence is simplified. In other words, every compound involved in the reaction can be replaced by a simple "simplified compound", which can be used directly into the estimation but has no negative effect on the estimation accuracy. Rules of choosing "simplified compounds" will be discussed below.

Estimations for the same 33 reactions as the experiment section were conducted and the following suggestions need to be considered.

(1) A balanced equation is necessary, or the proportion of the reactants and the products must be correct, and the phase should be noticed.

(2) The GCM can only get the standard enthalpy of formation in gas state, but the reaction phases are not always gas. Therefore, it is essential to transform the gas state to the liquid state by the enthalpy of vaporization.

(3) In a similar way, the GCM can only get the standard enthalpy of formation at $273.15 \mathrm{~K}$. It is necessary to revise the temperature from the $273.15 \mathrm{~K}$ to the reaction one by heat capacity to get a more exact result.

(4) Consult references to get as many as literature data of physical heats such as dissolution enthalpy, dilution enthalpy to decrease the errors.

(5) Several literatures have already give some formation enthalpy and error analysis ${ }^{45-48}$. It is always a good idea to crosscheck literature values against the estimation technique. Large differences should be checked further.

When the estimation of standard enthalpies of formation is done, the enthalpy of reaction may be found by equation (3). The estimated results are also listed in Table 1.

\section{Results}

\subsection{Results of comparisons}

As stated above, 33 comparisons were conducted and divided into 11 types according to the active functional group. The comparisons cover a range of reaction types including hydroge- 


\section{Table 1 Comparisons of 33 calorimetries and estimations}

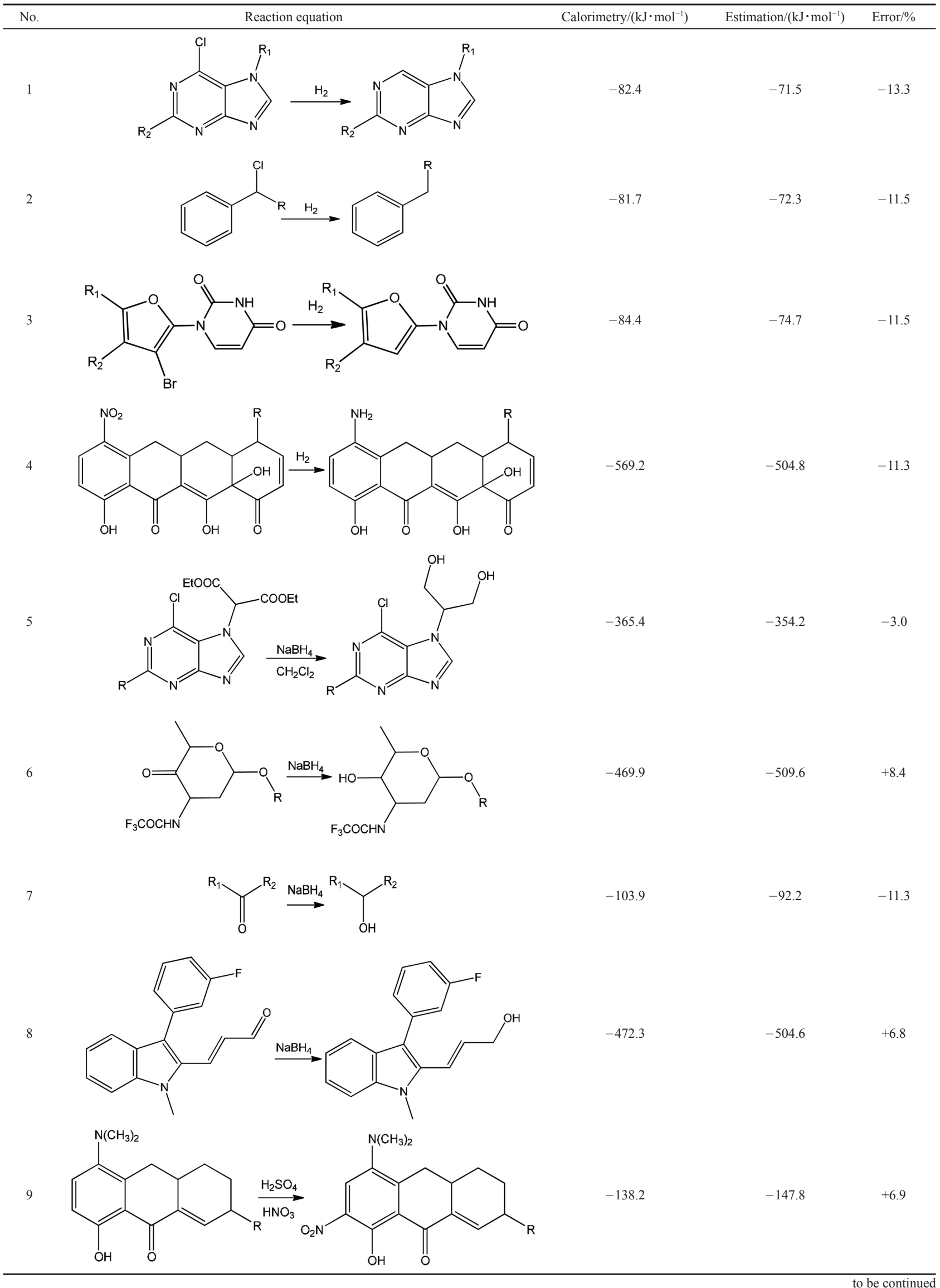


continued Table 1

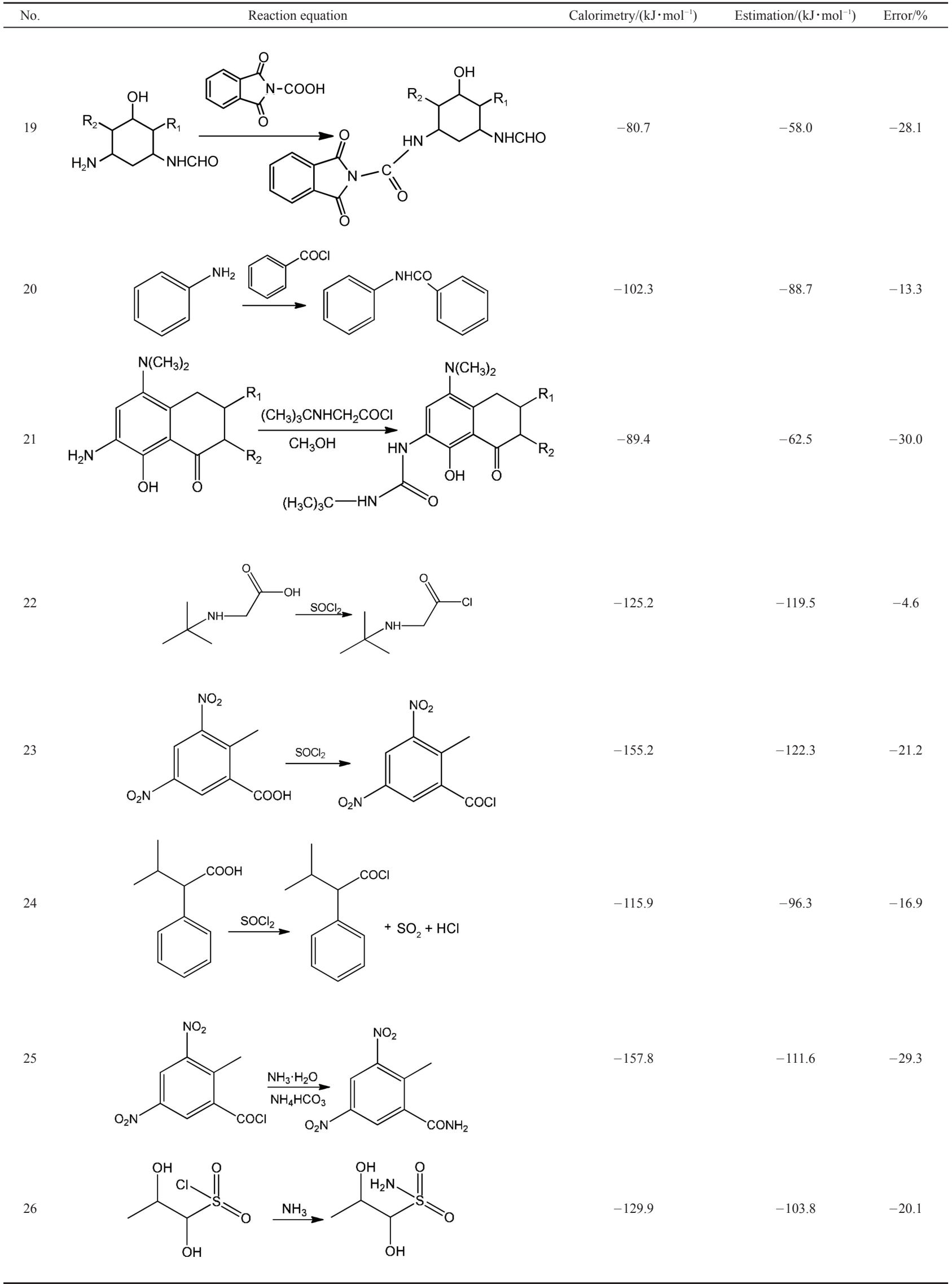




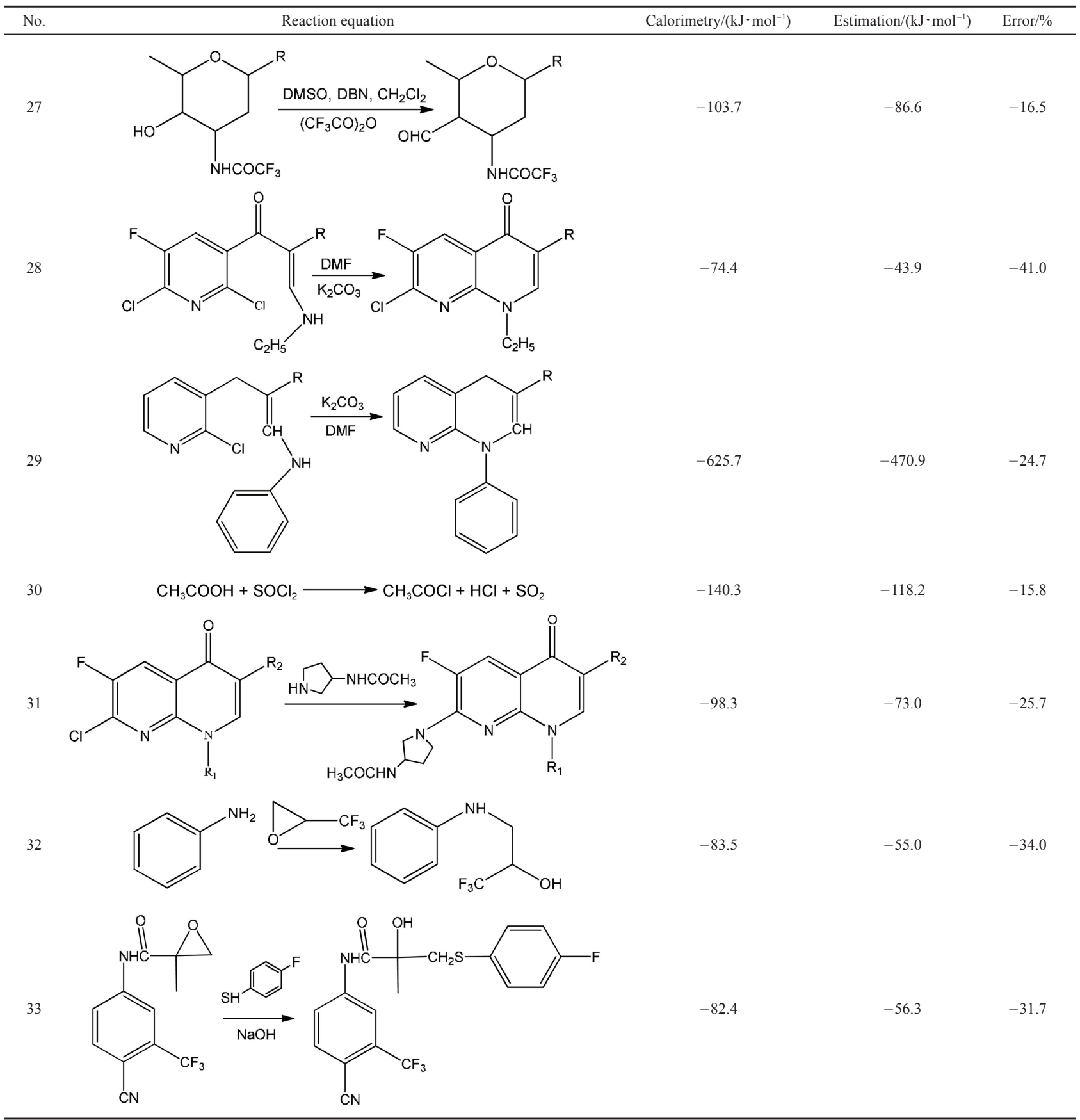

Some functional groups not related to the reaction are replaced to $\mathrm{R}$ to protect intellectual property. DMSO: dimethyl sulfoxide, DMF: $N, N$-dimethylformamide, DBN: 1,5-diazabicyclo[4.3.0]-5-nonene

nation, $\mathrm{NaBH}_{4}$ reduction, nitration, hydroxyl oxidation, amidation, amination, ester hydrolysis, producing nitrogenous compounds, breaking oxygen ring, esterification. An expected coincidence is that the reactions of the same type have similar errors. In general, the reactions of the same chemical types have a less than $5 \%$ error with each other. Reasons will be discussed below.

All the studied reactions were exothermic with some of them being even fairly large. Thus it can be seen that most reactions contain a huge heat-releasing potential. Obtaining the heat of reaction and making a proper design to deal with the output heat before flow-line production is a prerequisite to ensure safety.

As shown in Table 1, compared with calorimetric results, estimated values tend to be lower. This must be considered and enough design margin should be given if calorimetry is expensive or difficult to operate and estimation is a must when in practical design.

For clarity of the 33 comparisons, calorimetric reaction heats ( $\left.Q_{\text {calorimetry }}\right)$ are taken as the abscissa axis versus estimated results $\left(Q_{\mathrm{GCM}}\right)$ as the vertical axis and Fig.2 is plotted below. Every dot in Fig. 2 represents a comparison. Data below the diagonal represent 


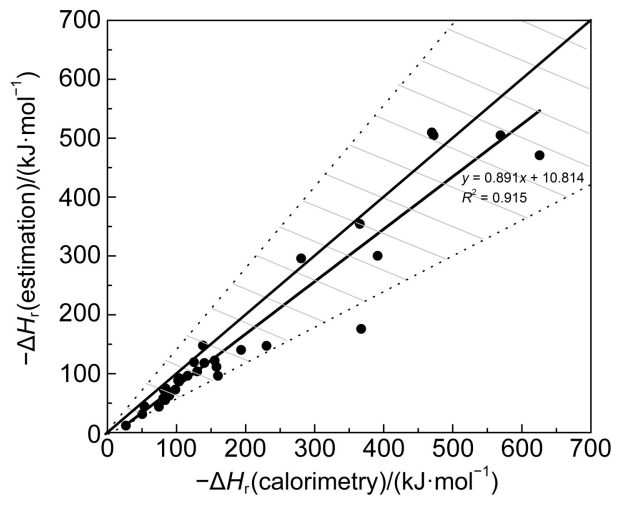

Fig.2 Comparisons of 33 groups of calorimetry and estimation results

In Fig.2, every dot stands for a reaction, and the thin line across the diagonal represents the $1: 1$ standard reaction heat. Data below the diagonal line represent reactions whose calorimetric reaction heat is larger than the estimated one (numerical), while above the diagonal line represent the opposite. The shadow between the two black dotted lines represents the error area whose errors are smaller than $40 \%$. As shown, 30 of 33 data appear in the $40 \%$ area, which means that about $91 \%$ reactions have a relative error smaller than $40 \%$. The bold solid line is the linear fit of the 33 data, which can be used as an approximate model of the estimation of reaction heat by the Benson GCM.

reactions whose calorimetric data are larger than estimated data. For these reactions in practical production, estimation value is smaller. Designing a process directly by estimated heat will be extremely dangerous and abundant design margin must be taken into account. In a similar way, data above the diagonal stand for the reactions whose estimated heats are larger. In these situations, although estimations have errors, results are secure for industry design.

\subsection{Distribution of errors and recommended correction coefficient}

It may be seen that 29 of 33 reactions investigated belong to the “estimation smaller" part, and the proportion reaches $88 \%$. Only 4 of 33 or $12 \%$ reactions have a calculated value larger than the experimented. Among all these 33 reactions, there are respectively $6,16,23,30,31$ comparisons having an absolute value of relative error within $10 \%, 20 \%, 30 \%, 40 \%, 50 \%$, and the percents reach $18.2 \%, 48.5 \%, 69.7 \%, 90.9 \%, 93.9 \%$ respectively. Fig. 3 shows the relative error distribution distinctly. For different reading habits, bar graph in the abscissa axis and line chart in the vertical axis are integrated in one figure.

Most reactions have errors within $30 \%$ on the whole. If $40 \%$ error is allowed, nearly $91 \%$ reactions reach the standard in total. Although the relative error is ubiquitous, multiplying corresponding correction coefficient can correct the estimated heat nearly to the actually one when in practical design. As Fig. 2 and Fig. 3 shown, about $90.9 \%$ reactions have a relative error smaller than $40 \%$. These reactions contain strong, medium, and trace exothermic types, which can represent most exothermic situations. In other words, taking 1.4 as the recommended correction coefficient for most reaction heats of practical reactions $(90.9 \%)$ is secure enough. If a safer design is needed, taking 1.5 as the correction coefficient is also available. However, as shown in Fig.3,

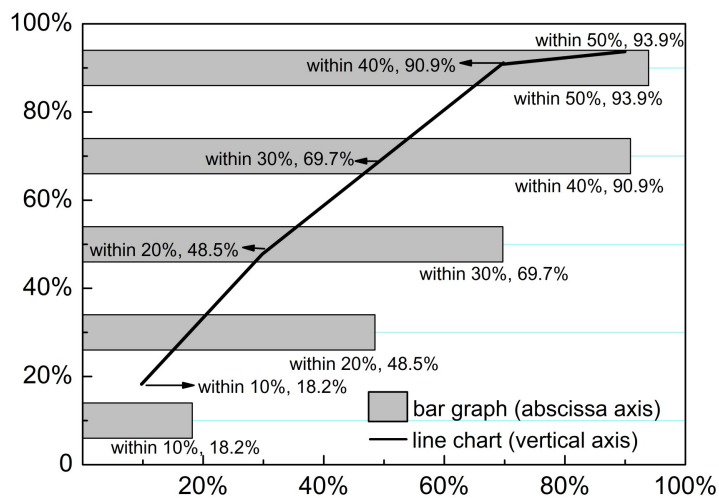

Fig.3 Distribution of relative errors of 33 comparisons

Bar graph in the abscissa axis and line chart in the vertical axis are for different reading habits. The bar graph is convenient to compare error sections with each other, while the line chart is convenient to read the increasing trend of each error section.

it is not always necessary to take 1.5 as the correction coefficient for the slower increase from $40 \%$ to $50 \%$.

At the same time, it is easy to find from Fig. 2 that 33 data can be approximately linearly modeled by one equation $y=0.891 x+$ 10.814 , and the goodness of fit reaches 0.915 . This equation can be regarded as a sketchy model of the estimation of reaction heat by the Benson GCM. When a reaction heat is needed by an industrial design, it is recommended to multiply the estimated results by 1.4 for an enough margin, while when a relatively accurate estimated result is needed, the linear equation model may be a better choice.

\subsection{Errors of different types of reactions}

Errors of different kinds of reactions are different from each other. In order to obtain more accurate estimated results, it is necessary to summarize the average error of every kind of reaction if the same kind of reactions have similar errors in number. It is noticed that the same kind of reactions have similar errors. Considering this, take the average errors of same kind of reactions to summarize in Table 2 as below.

The fact that the same kind of reactions have similar errors is inevitable. The essence of a reaction is old bond breaking and new bond forming, and the potential energy of the same bonds are the same. The differences among these errors come from different chemical conditions. There are enough reasons to have faith in Table 2 because quantities of similar elementary reaction comparisons have been checked by our process safety group including the above 33 reactions. The table can be used to correct the errors of estimation as close to the calorimetry.

Fig. 2 shows that 29 of 33 or $88 \%$ reactions have an estimated heat release which is smaller than the experiment. Main reasons are that many kinds of heat effect detected in the calorimetry cannot be all taken into account when in estimation. Dissolution, phase transition, dilution, salinization, hydrolysis, crystallization, mixing process, conversion rate, selectivity, side reactions are all unpredictable heat sources. As shown in Table 2, it is not difficult to draw that errors between different types of reactions are of great 
Table 2 Summary of average errors of typical synthetic reactions

\begin{tabular}{|c|c|c|c|}
\hline Type of reactions & Detailed feature & $\varepsilon$ & Error type \\
\hline \multirow[t]{2}{*}{$\mathrm{NaBH}_{4}$ reduction } & ester group to primary alcohol & $-1.50 \%$ & I \\
\hline & carbonyl to secondary alcohol & $-8.83 \%$ & I \\
\hline nitration & & $-7.10 \%$ & I \\
\hline \multirow[t]{3}{*}{ hydrogenation } & nitro to amidogen & $-11.30 \%$ & I \\
\hline & bromine atom reduction & $-11.50 \%$ & I \\
\hline & chlorine atom reduction & $-12.40 \%$ & I \\
\hline hydroxy to aldehyde group & & $-16.50 \%$ & I \\
\hline acyl chlorination & & $-14.63 \%$ & I \\
\hline amidation & & $-23.80 \%$ & II \\
\hline amination & & $-24.70 \%$ & II \\
\hline \multirow[t]{3}{*}{ esterolysis } & in a weak alkaline solution & $-8.30 \%$ & I \\
\hline & in a strong alkaline solution & $-39.80 \%$ & III \\
\hline & in other organic solutions & $-56.00 \%$ & IV \\
\hline nitrogen substitution & & $-30.47 \%$ & III \\
\hline oxygen ring broken & & $-32.85 \%$ & III \\
\hline \multirow[t]{2}{*}{ esterification } & acid-alcohol & $-29.01 \%$ & II \\
\hline & acyl chloride-alcohol & $-31.75 \%$ & III \\
\hline
\end{tabular}

$\varepsilon$ : average relative error

difference, and main reasons are followed.

(1) Hydrogenation, $\mathrm{NaBH}_{4}$ reduction, nitration, hydroxy oxidation and such reactions with a high heat release usually have a relatively smaller error and the estimation results are closer to the calorimetry ones. There are several reasons as listed below.

The most significant reason is that these reactions have a fairly large heat release and the heat detected in the experiment mainly comes from the reaction itself, or the energy difference between the new chemical bonds and the old ones. By comparison, heat of physical phenomenon and other chemical process is extremely small. At the same time, the mechanism of the GCM is mainly to consider the difference enthalpy in different groups or chemical bonds. Therefore, the literature group-values in previous work well describe the energy difference in kinds of groups, which leads these high-heat-release reactions to have a relative smaller error between the experiment and the estimation.

A secondary reason is that these reactions have fewer side reactions. For instance, hydrogenation can only reduce specific groups. For another example, nitration can only add nitro on the $o$ - and $p$-positions of benzene. For above two main and other reasons, these kinds of reactions have a small enough error. In practical industry, estimation technique is coming in handy and because of the very small errors of these reactions, estimation value has a high credibility. Multiplying the corresponding error correction coefficients can correct the estimation values to nearly the actual one. Taking margins into account and multiplying proper larger coefficients will make the design believable.

(2) Amidation and amination have $20 \%$ to $30 \%$ errors. Main source of the error is that the standard enthalpy of formation of the ammonia in which the estimation use are under gas state, but in reality, a large portion of ammonia gas dissolves in the solution which will increase the heat. Another source is the volatilization of ammonia. Although the error is a little larger, practical value in production is still very high. Amidation and amination are two central reactions to add nitrogen into the intermediate. Estimating the heats of reactions and taking design margins into account will help design the process safety.

(3) Esterification has a larger relative error. Main reasons are that esterification is carried out with a variety of catalyst, dehydrant, and other agents. Such agents are usually chosen concentrated sulfuric acid which will release amount of heat during the reaction when attenuated. At the same time, both reactant and product have a considerable heat of solution which leads to a larger error. What's more, reaction heats of esterification are always relatively small, which leads to relative larger errors. However, adequate correction can give a reaction heat close to the actual one, and elementary safety assessment can be carried out.

(4) Among all these comparisons, esterolytic reactions have the largest errors mainly for the following three reasons.

(a) Esterolytic reactions are endothermic in general, but dissolution, phase transition, and other physical process make the apparent heat effect are exothermic. A part of error comes from the heat conversion.

(b) Esterolytic reactions are reversible, and conversion usually may not be $100 \%$ completely. Estimation is used to calculate the $100 \%$ conversion heat, which leads to a larger heat absorption and the final estimated result showing a smaller heat release.

(c) Carboxyl and other acid groups will appear after hydrolyzation, and acid base neutralization will occur, which can release a great deal of heat.

For all above sources, ester hydrolyzation has a quite larger error between the estimation and experiment. Even so, the GCM still plays a significant role in this kind of reactions in the production. Estimated value can give the designer a primary screening and multiplying a larger error coefficient can get an approximate heat of reaction. 
Table $3 Q_{\mathrm{r}}$ for industrial applications

\begin{tabular}{ccc}
\hline Error type & Error range & $Q_{\mathrm{r}}$ for industrial applications \\
\hline I & $<20 \%$ & $1.2 Q_{\mathrm{GCM}}$ \\
II & $20 \%-30 \%$ & $1.3 Q_{\mathrm{GCM}}$ \\
III & $30 \%-40 \%$ & $1.4 Q_{\mathrm{GCM}}$ \\
IV & $>40 \%$ & $>1.4 Q_{\mathrm{GCM}}$ \\
\hline
\end{tabular}

\subsection{Applications of the estimated results}

When reaction heat is required but calorimetry is difficult to conduct, the GCM should be the first choice if no related literature is found. For safe process designs, Table 3 is proposed according to Table 2 to give $Q_{\text {recommended }}$ for industrial applications

It could follow the procedure as Fig.4.

\section{Discussion}

\subsection{Sources and analysis of errors}

Through the above analysis, it can be concluded that the value obtained by GCM is always smaller than the calorimetry. When error analysis is conducted, the estimated enthalpies of formations should be considered firstly. However, enthalpies of formation estimated using Benson groups are generally very accurate, within $10 \mathrm{~kJ} \cdot \mathrm{mol}^{-15,37}$. Therefore, the main sources of errors should not be the GCM itself.

Physical process related heat is one of the common sources of errors. Unknown physical interactions such as exothermic heats of dissolution, mixing, volatilization, attenuation, coordination, phase transferring, or crystallization can cause estimation errors.
Moreover, characters of reaction itself can also lead to estimation errors. Conversions, side reactions and secondary reactions are the main sources of errors. The more the conversion is to $100 \%$, the less error it will have. However, from a practical standpoint, the inability to accurately measure the conversion is not an issue because reactions with low conversion do not raise significant process safety concerns ${ }^{1}$. If the reactor can deal with the "more conversion", then it must be safer when the conversion is less. Therefore, designing process according to the estimation is reliable.

\subsection{Suggestions for estimation}

To conduct a more accurate estimation with a relative less error, several facts must be noticed.

(1) The form of the reactant and the product must be confirmed. A balanced equation does not mean a right one. For example, alkaline products will neutralize with the acid solution. To know the exact form of each substance can help get an accurate result.

(2) Conversion and selectivity should be mastered as much as possible. Instrumental characterization and literature are possible ways if there are no other methods to choose.

(3) Most reactions consist of several steps. Each step has its own "step heat", and the sum of "step heat" is the "reaction heat". If one of the steps release amount of heat but the others are endothermic, then the total reaction heat may not be that much. However, when in practical industry, the step with a huge of heat may cause an accident and it needn't consider the following steps. So it is necessary to get the actual steps of each equation.

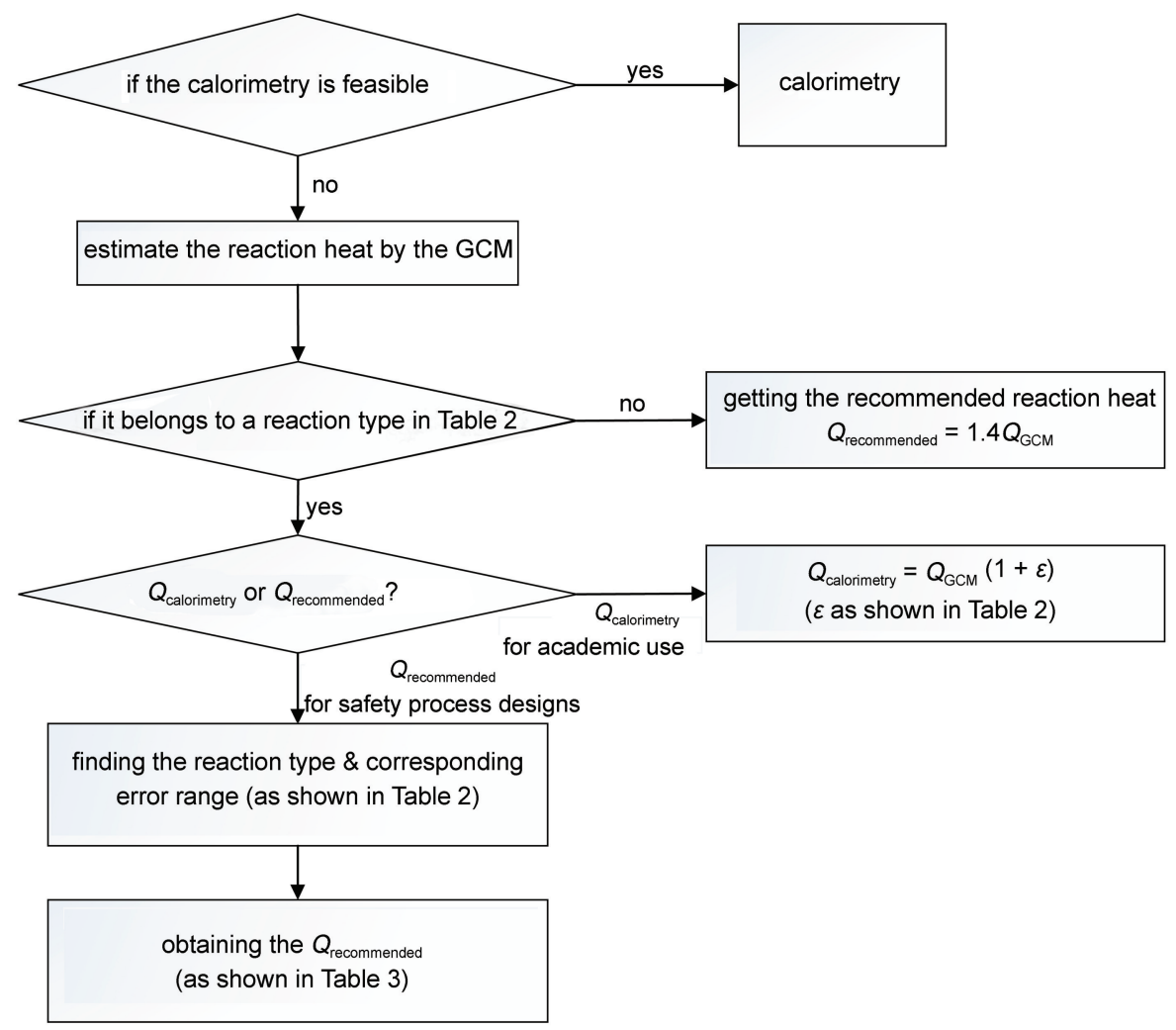

Fig.4 Procedure of the application of the estimated results 
(4) Non-condensable gas forming may take some heat away but increase the pressure of the reactor observably and make it an "untempered system", which need extra care to design the process.

(5) Both sides of the equation should use the same method of the GCM, but not random methods at a whim. By not mixing methods, the inherent assumptions in the estimation method are potentially carried across the equation and, therefore, potentially cancel.

\subsection{Basis of simplified compound}

Estimation section of this paper mentioned the phrase "simplified compound", which is used directly in the estimation to represent the entire complex compound but has no negative effect on the estimation accuracy. The actual heat of reaction is only related to the groups that change over the reaction. Parts that remain unchanged have no contribution to the reaction heat. Therefore, "simplified compound" is proposed to simplify the calculation.

Three rules to choose "simplified compounds" must be noticed:

First of all, reactive functional groups and its coterminous groups must be kept the same. For instance, derivative of nitrobenzene whose nitro is the reactive group is always replaced by nitrobenzene but not nitro methane, for the nitro is attached to a benzene ring directly.

Secondly, the first compound of a series is not a good choice for a simplified compound ${ }^{1}$. For example, heptanoic acid should better be replaced by acetic acid rather than formic acid.

Finally, phase states must be the same. If a gas simplified compound is chosen to take the place of a liquid one, the reaction process cannot be totally the same and the latent heat will lead to a larger error.

Only when the "simplified compounds" are chosen properly can the estimation be accurate.

\section{Conclusions}

This paper introduced two methods to obtain the heats of reactions and compared the results. The work mainly focuses on some typical chemical reaction types, compares the estimation and calorimetry results, gives a 1.4 correction coefficient for general reactions, proposes a sketchy model of the estimation of reaction heat by Benson GCM, summarizes the errors and the "correction coefficients" of typical kinds of reactions, and gives detailed analysis of different sources of the errors. When reaction heats are needed in academic and industrial use and the calorimetric experiments are not available, the GCM is a recommended way to obtain the $Q_{\text {calorimetry }}$ for researches and the $Q_{\text {recommended }}$ for industrial designs after a correction by Table 2, Table 3, and Fig.4.

Based on this work, a proper screening method of the reaction heat for practical design may be proposed which could potentially contribute to building up a more accurate estimation method of reaction heat in the future.

Acknowledgment: The authors would like to appreciate the assistance of Mr. David Haywood and Mr. Mark Hoyle from Astra
Zeneca.

\section{References}

(1) Weisenburger, G. A.; Barnhart, R. W.; Clark, J. D. Org. Process Res. Dev. 2007, 11 (6), 1112. doi: 10.1021/op700173h

(2) Frurip, D. J. Determination of Chemical Process Heats by Experimentation and Prediction. In International Symposium on Runaway Reactions and Pressure Relief Design; Melhem, G. A., Fisher, H. G. Eds. American Institute of Chemical Engineers: New York, 1995; p 95.

(3) Marrero, J.; Gani, R. Fluid Phase Equilib. 2001, 183, 183. doi: 10.1016/S0378-3812(01)00431-9

(4) Saraf, S. R.; Rogers, W. J.; Mannan, M. S. 2003, 98 (1), 15. doi: 10.1016/S0304-3894(02)00314-X

(5) Curtiss, L. A.; Redfern, P. C.; Frurip, D. J. Theoretical Methods for Computing Enthalpies of Formation of Gaseous Compounds. In Reviews in Computational Chemistry; Lipkowitz, K. B., Boyd, D. B. Eds.; Wiley-VHC: New York, 2000; Vol. 15, p 147.

(6) Barkert, U.; Allinger, N. L. Molecular Mechanics; American Chemical Society: Washington D.C, 1982; pp 174-175.

(7) Saraf, S. R.; Rogers, W. J.; Ford, D. M. Fluid Phase Equilib. 2004, 222, 205. doi: 10.1016/j.fluid.2004.06.048

(8) Joback, K. G.; Reid, R. C. Chem. Eng. Commun. 1987, 57 (1), 233. doi: $10.1080 / 00986448708960487$

(9) Lydersen, A. L. Estimation of Critical Properties of Organic Compounds; College Engineering University Wisconsin, Engineering Experimental Station Report 3: Madison, WI, April, 1955.

(10) Ambrose, D. Correlation and Estimation of Vapor-Liquid Critical Properties. I. Critical Temperatures of Organic Compounds; National Physical Laboratory: Teddington, UK, NPL Report Chem., 92, September 1978.

(11) Klincewicz, K. M.; Reid, R. C. AIChE J. 1984, 30 (1), 137. doi: 10.1002/aic.690300119

(12) Lyman, W. J.; Reehl, W. F.; Rosenblatt, D. H. Handbook of Chemical Property Estimation Methods; American Chemical Society: Washington, DC, 1990.

(13) Horvath, A. L. Molecular Design; Elsevier: Amsterdam, 1992; p 637.

(14) Wang, X. L.; Dong, H.; Zeng, Z. H.; Wu, C. J. Solution Chem. 2015, 44, 67. doi: 10.1007/s10953-014-0286-9.

(15) Zeng, Z. X.; Li, X. N.; Xue, W. L.; Zhang, C. S.; Bian, S. C. Ind. Eng. Chem. Res. 2010, 49, 5543. doi: 10.1021/ie9014342

(16) Basařová, P.; Svoboda, V. Fluid Phase Equilib. 1995, 105 (1), 27. doi: 10.1016/0378-3812(94)02599-V

(17) Benkouider, A. M.; Kessas, R.; Guella, S. J. Mol. Liq. 2014, 194, 48. doi: 10.1016/j.molliq.2014.01.006

(18) Conilio, L.; Daridon, J. L. Fluid Phase Equilib. 1997, 139, 15. doi: 10.1016/S0378-3812(97)00143-X

(19) Huo, Y.; Xia, S.; Zhang, Y. Ind. Eng. Chem. Res. 2009, 48 (4), 
2212. doi: $10.1021 /$ ie 8011215

(20) Gharagheizi, F.; Ilani-Kashkouli, P.; Sattari, M. J. Mol. Liq. 2014, 190, 223. doi: 10.1016/j.molliq.2013.10.019

(21) Gharagheizi, F.; Salehi, G. R. Thermochim. Acta 2011, 521 (1), 37. doi: $10.1016 /$ j.tca.2011.04.001

(22) Zhang, X.; Kobayashi, N.; He, M. Energy Procedia 2014, 61, 492. doi: 10.1016/j.egypro.2014.11.1156

(23) Carreón-Calderón, B.; Uribe-Vargas, V.; Ramírez-de-Santiago, M. Ind. Eng. Chem. Res. 2014, 53 (13), 5598. doi: 10.1021/ ie $403967 z$

(24) Cunico, L. P.; Ceriani, R.; Guirardello, R. Chem. Eng. Trans. 2013, 32, 535. doi: 10.3303/CET1332090

(25) Albert, J.; Müller, K. Ind. Eng. Chem. Res. 2014, 53 (44), 17522. doi: 10.1021/ie503366p

(26) Lazzús, J. A.; Pulgar-Villarroel, G. J. Mol. Liq. 2015, 209, 161. doi: 10.1016/j.molliq.2015.05.030

(27) Lazzús, J. A. Thermochim. Acta 2012, 528, 38. doi: 10.1016/j. tca.2011.11.004

(28) Lazzús, J. A. J. Mol. Liq. 2012, 168, 87. doi: 10.1016/j. molliq.2012.01.011

(29) Sattari, M.; Gharagheizi, F.; Ilani-Kashkouli, P. J. Therm. Anal. Calorim. 2014, 115 (2), 1863. doi: 10.1007/s10973-013-3474-8

(30) Valderrama, J. O.; Forero, L. A.; Rojas, R. E. Ind. Eng. Chem. Res. 2015, 54 (13), 3480. doi: 10.1021/acs.iecr.5b00260

(31) Nancarrow, P.; Lewis, M.; AbouChacra, L. Chem. Eng. Technol. 2015, 38 (4), 632. doi: 10.1002/ceat.201400667

(32) Argoub, K.; Benkouider, A. M.; Yahiaoui, A. Fluid Phase Equilib. 2014, 380, 121. doi: 10.1016/j.fluid.2014.08.003

(33) Regenass, W. J. Therm. Anal. Calorim. 1997, 49 (3), 1661. doi: 10.1007/BF01983727

(34) Zogg, A.; Stoessel, F.; Fischer, U. Thermochim. Acta 2004, 419 (1), 1. doi: 10.1016/j.tca.2004.01.015
(35) Benson, S. W.; Cruickshank, F. R.; Golden, D. M. Chem. Rev. 1969, 69 (3), 279. doi: 10.1021/cr60259a002

(36) Benson, S. W. Thermochemical Kinetics, 2nd ed.; John Wiley: New York, 1976.

(37) Cohen, N.; Benson, S. Chem. Rev. 1993, 93 (7), 2419 doi: 10.1021/cr00023a005

(38) Poling, B. E.; Prausnitz, J. M.; O'Connell, J. P. The Properties of Gases and Liquids, 5th ed.; McGraw-Hill: New York, 2001; p 314.

(39) Domalski, E. S. Hearing, E. D. J. Phys. Chem. Ref. Data 1993, 22 (4), 805. doi: $10.1063 / 1.555927$

(40) Chemical Thermodynamic and Energy Release Evaluation (CHETAH), Version 8.0; available through the ASTM website: http://www.astm.org/ cgi-bin/SoftCart.exe/BOOKSTORE/ PUBS/1026.htm?L + mystore + vkkc4412.

(41) Frurip, D.; Britton, L.; Fenlon, W. Process Saf. Prog. 2004, 23 (4), 266. doi: 10.1002/prs. 10046

(42) Irikura, K. K.; Frurip, D. J. Computational Thermochemistry; ACS Symposium Series 677, American Chemical Society: Washington, DC, 1998.

(43) Gasteiger, J. Comput. Chem. 1978, 2, 85. doi: 10.1016/00978485(78)87006-5

(44) Margrave, J. L. J. Chem. Educ. 1955, 32, 52

(45) Cox, J. D.; Pilcher, G. Thermochemistry of Organic and Organometallic Compounds; Academic Press: London, 1970; p 523.

(46) Pedley, J. B. Thermochemical Data and Structures of Organic Compounds; Thermodynamics Research Center: Texas, 1994; Vol. 1.

(47) Wagman, D. D. J. Phys. Chem. Ref. Data 1982, 11, Supplemental No. 2.

(48) http://webbook.nist.gov/chemistry/. 